\title{
Modeling the Internal Control Constraint of University Research Funding System
}

\author{
Jiacan Wang $\mathbb{D}^{1}$ and Liangzhang $\mathrm{Hu} \mathbb{D}^{2}$ \\ ${ }^{1}$ School of Economics and Management, Nanchang University, Nanchang 330031, China \\ ${ }^{2}$ Jiluan Academy, Nanchang University, Nanchang 330031, China
}

Correspondence should be addressed to Jiacan Wang; wangjiacan@ncu.edu.cn

Received 11 June 2021; Accepted 7 July 2021; Published 16 July 2021

Academic Editor: Daqing Gong

Copyright (C) 2021 Jiacan Wang and Liangzhang Hu. This is an open access article distributed under the Creative Commons Attribution License, which permits unrestricted use, distribution, and reproduction in any medium, provided the original work is properly cited.

\begin{abstract}
With the in-depth development of the trend of scientific and technological innovation and the implementation of the "Double First-Class" strategy, universities shouldering the scientific research task are constantly promoting the development of scientific research projects with the support of national policies and the scientific research funds are also significantly increased. However, due to the defects of the existing internal control system of scientific research funds in universities, scientific research corruption cases occur frequently. Therefore, it is urgent to build a strong internal control system of scientific research funds to meet the development requirements of the "Double First-class" strategy. For this reason, this paper uses the method of case study, combines the five elements of the COSO internal control system and the internal control norms of Chinese administrative institutions, selects three typical cases of university research corruption, and finally constructs the internal control constraint model of university research funds. This model puts forward suggestions to improve the internal control system of the scientific research funds in universities from four aspects of environmental constraint, psychological constraint, control constraint, and regulatory constraint. Through the construction of the model, it is expected to provide some reference for the construction of the internal control system of scientific research funds in universities.
\end{abstract}

\section{Introduction}

With the development of economy and society, the role of science and technology has become more and more powerful. Therefore, the country has provided a series of policy support to promote the innovation and development of science and technology. Under the implementation of "Double First-Class" strategy, especially, the country has invested huge funds for the construction of "Double FirstClass" universities, such as the economically developed areas of Beijing, Shanghai, and Guangzhou, among which Beijing has invested nearly 10 billion yuan, Shanghai 3.6 billion yuan in the first stage, and Guangdong 30 billion yuan directly. The total funding from the National Natural Science Foundation of China reached 31.1 billion yuan in 2019. It is conceivable that the country attaches great importance to the "Double First-Class" strategy and determination. As the frontier position of scientific and technological innovation, universities also actively carry out scientific research activities under the incentive of "Double First-class" strategy. However, because the internal control system of universities is not perfect, there are many blind spots in the supervision of scientific research funds, which leads to some participants of scientific research projects to take advantage of the defects of the internal control system of universities to seek personal gains, thus causing huge losses of funds. For example, in recent years, the China Commission for Discipline Inspection has reported more than 30 cases of corruption in universities in one year, including some cases involving the embezzlement of research funds. Therefore, it is urgent to constrain scientific research behaviour and manage scientific research funds through strong internal control system, so as to promote the implementation and development of "Double First-Class" strategy. Among the numerous corruption cases of university scientific research, the most typical one is the corruption cases of Ning Li and Lei Zhang. 
It can be seen that the internal control of universities still has defects.

Based on this, from Ning Li and Lei Zhang corruption case, Shandong University Zhao-Ping Liu corruption case, and many other cases summarized the general defects of the internal control system of university research funds, from the perspective of the internal control system of university research funds to the constraints of researchers, and put forward the internal control model of university research funds. Through this constraint model, the research funds can be managed effectively, and the research projects can be carried out in an orderly way.

\section{Literature Review}

With the occurrence of a series of cases of scientific research corruption in universities, the effective supervision and use of scientific research funds in universities are particularly important. In the domestic research, in terms of internal control theory, Lin [1] summarized the essence of internal control from three aspects, institutional theory, procedure theory, and system theory, and explained their respective roles in enterprise operation and management. Tian [2] further detailed the application of internal control theory in administrative institutions. In terms of internal control research in universities, Li and Chang [3] believed that there are great risks in the operation process of construction funds for first-class disciplines at present, and it was urgent to accelerate the construction of internal control and risk management system in universities. Li [4] studied the construction of internal control in universities under the background of clean government and analysed the practical significance and principles of its construction in detail. For the research on the internal control of research funds in universities, Zou [5] analysed the activity control of research funds in universities and provided suggestions from the perspective of horizontal research funds. Yang and Xie [6] analysed the risks of university research funds under the government accounting system from the perspective of internal control at the unit level and business level and provided relevant solutions. In foreign countries, Nguyen and Meek [7] analysed and summarized the literature of internal control from the perspective of system work and put forward a comprehensive understanding of internal control. Nguyen [8] analysed problems in the research structure and organization of four of Vietnam's top universities and found a lack of specialization in research management. As a kind of risk, scientific research problems in colleges and universities need to be prevented by effective measures. Leonce et al. [9] pointed out that internal control can effectively reduce innovation risks, so internal control can effectively solve the problems existing in university scientific research. It can be seen that the previous domestic research on the internal control of university research funds focuses on a certain factor in the internal control, while the foreign research rarely starts from the internal control directly. In addition, it is more targeted to study the problem, but few scholars study the cases of scientific research corruption in universities.
To sum up, the research on the internal control of university research funds still has a great value and space. Moreover, previous studies are on lack of model presentation, which is relatively not stereoscopic and visualized. Based on this, this study selects Ning Li, Lei Zhang, and other typical cases of corruption of scientific research funds in many universities and constructs the internal control constraint model of scientific research funds in universities from actual cases.

\section{Research and Design}

3.1. Case Selection. This paper chooses the method of case study on the basis of the research content, mainly because the method based on case study is consistent with the research content of this paper, and the case study method can analyse phenomena in a more in-depth and comprehensive way and find solutions to existing problems more effectively [10]. At the same time, this is a multicase study, because, compared with single-case studies, multicase studies can overcome the limitation of the lack of universality of the results in singlecase studies to a certain extent, to analyse the phenomenon more comprehensively. On the choice of the object of study, this research from the Sky Eye software refers to obtain relevant information, in comprehensive consideration of scientific research in universities on corruption cases, and chooses three more typical cases, Ning Li and Lei Zhang corruption (2020; sentence times are shown in brackets, similarly hereinafter), Shandong University Zhao-Ping Liu corruption (2015), and Ying-Xv Chen corruption (2014). The selection of cases is mainly based on the following reasons. First, the three corruption cases involve a large amount of money and cause great social attention. The public is more aware of these three corruption cases, which is conducive to the understanding and dissemination of the study results. Second, the main corrupt officials in these three cases all hold high positions, so the research results can arouse the attention of the society. Third, there are similarities and differences in the corruption methods of these three cases, which are conducive to mutual verification and mutual supplement of the research contents. Therefore, this paper selects these three corruption cases for qualitative analysis and constructs the internal control constraint model of university research funds.

3.2. Case Description. Based on the fact that the three cases happened in different times (see Table 1), this paper will make a brief statement of the cases according to the chronological order, and the specific and complete contents are available for request.

Ying-xv Chen, the former executive vice president of the College of Environment and Resources of Zhejiang University, took advantage of his position as the general director of the national major project "Tiao-xi Project" from 2008 to 2011 to list two companies under his control as the assistance units outside the project and the doctoral students under his tutoring as the main participants of the course project. Then, the two affiliated companies were used to obtain $10,226,646$ yuan of special scientific research funds by means of false 
TABLE 1: Basic information of the cases.

\begin{tabular}{|c|c|c|c|c|c|}
\hline Case name & $\begin{array}{l}\text { Sentence } \\
\text { time }\end{array}$ & $\begin{array}{l}\text { Main } \\
\text { person }\end{array}$ & Position & $\begin{array}{c}\text { Corruption } \\
\text { amount }\end{array}$ & Corruption means \\
\hline $\begin{array}{l}\text { Shandong University } \\
\text { Zhao-Ping Liu } \\
\text { embezzlement case }\end{array}$ & 2020 & $\begin{array}{l}\text { Zhao- } \\
\text { Ping Liu }\end{array}$ & $\begin{array}{c}\text { Director of Experimental Animal Centre and } \\
\text { deputy director of New Drug Evaluation Centre } \\
\text { of Shandong University }\end{array}$ & $\begin{array}{l}3.418 \text { million } \\
\text { yuan }\end{array}$ & $\begin{array}{l}\text { Falsely making out } \\
\text { invoice }\end{array}$ \\
\hline $\begin{array}{l}\text { Zhejiang University } \\
\text { Ying-Xv Chen } \\
\text { embezzlement case }\end{array}$ & 2014 & $\begin{array}{l}\text { Ying-Xv } \\
\text { Chen }\end{array}$ & $\begin{array}{c}\text { Former executive vice president of School of } \\
\text { Environment and Resources }\end{array}$ & $\begin{array}{l}9.454974 \\
\text { million yuan }\end{array}$ & $\begin{array}{c}\text { Falsely making out } \\
\text { invoice } \\
\text { Dummy contract } \\
\text { Virtual braiding } \\
\text { accounts }\end{array}$ \\
\hline $\begin{array}{l}\text { China Agricultural } \\
\text { University }\end{array}$ & & & $\begin{array}{l}\text { Academician of Chinese Academy of } \\
\text { Engineering, China Agricultural University }\end{array}$ & $\begin{array}{l}34.1 \text { million } \\
\text { yuan }\end{array}$ & $\begin{array}{l}\text { Falsely making out } \\
\text { invoice }\end{array}$ \\
\hline $\begin{array}{l}\text { Ning Li and Lei Zhang } \\
\text { corruption case }\end{array}$ & 2015 & Ning Li & Professor & $\begin{array}{l}\text { One million } \\
\text { yuan }\end{array}$ & $\begin{array}{l}\text { Misstating } \\
\text { expenditure on } \\
\text { services }\end{array}$ \\
\hline
\end{tabular}

invoice writing, false contract writing, and false accounting, among which several hundred thousand yuan could not be identified, and the total amount of embezzled scientific research funds was finally confirmed to be 9,454,974 yuan.

From 2009 to 2012, Zhao-Ping Liu, the former director of the Animal Experiment Centre of Shandong University, took advantage of his position to falsely issue invoices from Shanghai Xingang Experimental Animal Farm, in which he invested, under the guise of needing to purchase experimental animals, with a total amount of 2.852 million yuan. In addition, Liu solicited public funds of Shandong University in the same way for several times, and the amount of money obtained reached more than 9.21 million yuan. After deducting the part that should be personal income, the actual amount reached more than 3.418 million yuan, which was used to pay for the equipment and project of his company. To improve the enthusiasm of the centre staff, Liu also distributed the quarterly bonus of research projects in the form of research fund commission. Meanwhile, Zhang, the former director of the Administrative Department of the New Drug Evaluation Centre of Shandong University, and Yin, the former laboratory technician of the Experimental Animal Centre of Shandong University, provided help to Liu in accordance with his instructions even though they knew that he had defrauded public funds. Among them, after deducting part of personal income, Zhang participated in taking public funds of more than 1.689 million yuan and Yin participated in taking public funds of more than 0.475 million yuan.

Between 2008 and 2012, Ning Li, an academician at the Chinese Academy of Engineering, took advantage of his position to appoint two companies in which he was the general manager of the project as assistants, and instructed Zhang Lei and other relevant personnel to steal his and other project leaders' labour fees by falsely listing labour workers and increasing the amount of personal labour fees. At the same time, he signed a false contract with two companies to get the rebate of two million yuan and one million yuan, respectively. To sum up, Ning Li embezzled over 37.56 million yuan of scientific research funds through false invoice writing and false increase of labour fees and actually embezzled over 34.1 million yuan after related reduction.
3.3. Case Analysis. This paper first uses fraud triangle theory to conduct a preliminary analysis of three cases and then combines it with Gone theory for further research. It is found that the current internal control system of scientific research funds in universities mainly has five defects, such as weak legal concept, slow risk identification, improper control of scientific research expenditure process, poor information flow of the scientific research management department, and ineffective supervision.

3.3.1. Weak Legal Concept. The main perpetrators of the three cases were all from well-known 985 universities in China. The perpetrators had a higher level of knowledge and legal awareness than ordinary people and know the consequences of illegal acts. However, driven by interests and lacking a detailed understanding of the laws and regulations, they were desperate to try the law. The main reasons for the weak legal concept of university researchers are as follows:

(1) Universities Not Thoroughly Implementing Relevant Laws and Regulations. Universities have not conducted a thorough and detailed organizational study of the national laws on the use of scientific research funds. Moreover, universities do not carry out their own regulations on the use of research funds, leading to the lack of understanding of the use of research funds by researchers, which further weakens the binding force of laws and regulations. Simultaneously, to a certain extent, it condones the illegal use of scientific research funds.

(2) Researchers' Contempt for Laws and Regulations. Instead of dissuading others when they know they have committed illegal acts, researchers provide help and collude with them according to their instructions. Tempted by interests, they break the law knowingly and fail to keep the "red line" of the law.

(3) The Affiliate's Disregard for Laws and Regulations. The affiliated companies that provide help to the corrupt personnel of university research funds are indifferent to the laws and regulations governing the 
management of university research funds and fail to stop the illegal activities in time but instead try to make profits from them.

3.3.2. Slow Risk Identification. Throughout the three cases, it usually takes several years for universities to find out the illegal and irregular behaviours of researchers. During these years, the illegal and irregular behaviours were not stopped in time, which caused huge losses of university research funds and had a bad impact on the scientific research atmosphere. If colleges and universities fail to timely identify the risks that may occur in the use of scientific research funds and fail to timely stop the risks that are occurring, such a cycle of repetition will easily encourage researchers' fluke psychology.

\subsubsection{Improper Control of Scientific Research Expenditure} Process. In all three cases, the corruption was carried out in similar ways, by fabricating false stories to defraud research funds. This kind of corruption means is manifested in the improper control of the process of scientific research expenditure. First of all, the budget of scientific research funds is improperly controlled. The universities fail to set up the budget in a scientific and reasonable way and fail to scientifically design the evaluation standards for the effect and quality that should be achieved at each stage of the scientific research project. Instead, they are only satisfied with the materials that should be submitted at each stage. Through false invoices, false contracts, and other means and after certain procedures, the criminals could obtain funds no matter whether it was true or reasonable, resulting in a large number of scientific research funds not being used reasonably and effectively. In the budget implementation stage, the progress of scientific research projects and the expenditure of funds failed to be timely feedback. In the budget assessment stage, only the final scientific research results are submitted, and the ratio between them and the scientific research funds is lack of scientific assessment and evaluation. Second, accounting system control is improper. Some universities have weak control over the accounting system of scientific research funds and fail to accurately and timely review and check the related business expenses of scientific research funds, so that some university researchers can cheat scientific research funds by falsely listing labour personnel and falsely increasing the amount of labour fees. Finally, the contract is not properly controlled. The contract management assessment and responsibility investigation system in colleges and universities is not perfect, and the contracts concluded in scientific research projects cannot be timely and effectively reviewed, so that the authenticity of the contracts cannot be effectively distinguished.

3.3.4. Poor Information Flow of the Scientific Research Management Department. According to the positions of the perpetrators in the three cases, they were all important leaders of a certain department in the university. Simultaneously, they were also the main person in charge of a project. However, information asymmetry exists between the person in charge and members, which leads to the decrease of timeliness and effectiveness of information communication. In universities, this influence is reflected in the horizontal and vertical communication system of information. Vertical communication is not smooth: the university scientific research management department fails to timely conduct research and analysis on the specific situation of scientific research projects and the use of scientific research funds. Therefore, the problems existing in the process of scientific research projects cannot be solved in time. Horizontal communication is poor: the relevant information of the scientific research project is not well communicated between relevant management departments, which leads to incomplete grasp of the progress of the scientific research project and failure to effectively identify the existing problems. The information flow between the scientific research administrative departments in universities is not smooth, which leads to the information asymmetry between them and the participants of the scientific research projects and then increases the risk of the researchers' illegal behaviours.

3.3.5. Ineffective Supervision. The occurrence of three cases of scientific research corruption was an important embodiment of the ineffective supervision of universities. From the position of the perpetrator, assisting company, and personnel of the case, it can be found that the supervision of scientific research funds in universities is mainly embodied in horizontal supervision, vertical supervision, and two-way supervision. First of all, in the aspect of vertical supervision, the research management departments of universities and colleges fail to realize effective vertical management of the use of research funds. Usually, when the research funds are supervised by the research management department, which plays the main supervisory role, the supervision of colleges and other institutions is easily weakened. In terms of horizontal management, supervision among research group members is weak. Among the members of the research group, due to the information asymmetry between the project leader and the participants, the project participants cannot effectively supervise the behaviour of the project leader. In terms of internal and external supervision, universities lack an effective internal control system, and offcampus companies cooperating with university researchers have insufficient motivation to supervise researchers' illegal behaviours, leading to ineffective internal and external supervision.

3.4. Model Construction. Based on the detailed analysis of three cases, this paper draws on the induction of internal control elements in the article "Internal Control-Integrated Framework" issued by COSO Committee and classifies the previously mentioned issues into the five elements of internal environment, risk assessment, control activities, information and communication, and internal supervision. In view of the previously mentioned problems, the concrete and effective solutions are discussed, respectively. Then, a 
large number of relevant literatures are referred to, in order to summarize and classify the model elements of each measure as accurately as possible and build a scientific and reasonable model. Table 2 shows the specific ideas and process of model construction. Based on Table 2, this paper builds a constraint model for internal control of scientific research funds (see Figure 1).

\section{Model Elaboration}

The internal control constraint model of scientific research funds in universities (EPCR model for short) is a model for effective management of scientific research behaviours and funds based on the internal environment, risk assessment, control activities, information and communication, and internal supervision, which takes universities as the main body and aims at improving the internal control system. The EPCR model is described in detail as follows.

\subsection{Environmental Constraint. Environmental constraint} refers to the constraint on the behaviours of the participants of scientific research activities in universities through the influence of environment. (1) External environmental constraint mainly refers to the behavioural constraints of researchers formed by the laws and regulations on the management of university research funds promulgated by the country. Therefore, the country should constantly improve the legal system to regulate the use of scientific research funds in universities and implement it in universities. Universities should actively organize all personnel involved in scientific research projects to study the laws on the management of scientific research funds promulgated by the country, so that each participant in scientific research activities can know the law and abide by the law under the constraints of the law. (2) Internal environmental constraint refers to the behavioural constraints formed by the regulations on the use of scientific research funds in universities on the participants in scientific research activities. Universities should improve their own internal standards for the use of scientific research funds and effectively implement relevant laws and regulations through training and education. Simultaneously, they should actively shape the core values of scientific research in universities and create an academic atmosphere of law-abiding, honest, and trustworthy.

4.2. Psychological Constraint. Psychological constraint refers to the psychological constraints on the behaviours of the participants of scientific research projects. (1) Endogenous psychology refers to the psychology of fluke and risk taking caused by the defects in risk identification of scientific research project participants in universities. Universities should speed up the construction of efficient risk identification mechanism and timely identify the existing or possible risks. They should further evaluate the risks on the basis of risk identification, take effective measures to solve the problems, and exert pressure on researchers psychologically, so as to achieve the effect of nip in the nip. (2) External psychological constraint refers to using relevant information to exert psychological pressure on the illegal behaviours of the participants of scientific research projects in order to restrain them. This requires universities to conduct timely research on the situation of scientific research activities and, on this basis, collect, analyse, and sort out relevant information. Simultaneously, information sharing should be strengthened among departments involved in scientific research management in universities so as to fully grasp the progress of scientific research projects. Illegal and irregular behaviours found in the process of scientific research should be stopped in time, and relevant personnel should be warned constantly to exert psychological pressure on them from the outside, so as to achieve the purpose of behavioural restraint.

4.3. Control Constraint. Control constraint refers to the effective risk control of various activities of scientific research by taking measures to restrain scientific research behaviours. (1) Universities should scientifically compile the budget of scientific research funds, design scientific quality assessment methods for scientific research projects, and reasonably match the effects of each stage of scientific research projects with the scientific research funds. In the budget implementation stage, timely feedback on the progress of scientific research projects and the expenditure of funds is performed, and corresponding treatment for the expenditure that does not conform to the standard is made. In the course of budget assessment, strict assessment shall be made and corresponding rewards shall be given according to the assessment of the quality of scientific research achievements. The rational use of scientific research funds can be promoted through scientific budget control. (2) Universities should strictly review and reexamine the flow of research funds, ensure that the use of funds is legal and compliant, and report unreasonable business in time, so as to effectively identify and solve illegal behaviours in research activities. The perfect accounting system is used to control and restrain the illegal activities in scientific research activities. (3) It is necessary for universities to cooperate with legal departments or other departments to conduct centralized management of contracts and improve the assessment and accountability system. The contracts signed between researchers and enterprises should be inspected and assessed regularly. Any problems in them should be stopped in time and the relevant personnel should be held responsible. Through the powerful contract control, the contract behaviour is restrained, and the contract risk is prevented.

4.4. Regulatory Constraint. Regulatory constraint means to supervise scientific research activities and restrain scientific research behaviours in real time by establishing a strong regulatory system. (1) Vertical regulatory constraint mainly refers to the supervision of research management departments and colleges in research activities and timely discovery and correction of illegal behaviours in research activities. Therefore, universities should improve the vertical supervision mechanism and reasonably divide the 
TABLE 2: Model construction process.

\begin{tabular}{|c|c|c|c|c|}
\hline Model & Main module & Module element & Factor analysis & Problem \\
\hline \multirow{5}{*}{$\begin{array}{l}\text { The internal control } \\
\text { constraint model of } \\
\text { university research funds }\end{array}$} & $\begin{array}{l}\text { Environmental } \\
\text { constraint }\end{array}$ & $\begin{array}{l}\text { External environmental } \\
\text { constraint } \\
\text { Internal environmental } \\
\text { constraint }\end{array}$ & $\begin{array}{c}\text { Internal } \\
\text { environment }\end{array}$ & Weak legal concept \\
\hline & $\begin{array}{l}\text { Psychological } \\
\text { constraint }\end{array}$ & $\begin{array}{c}\text { Endogenous psychology } \\
\text { constraint }\end{array}$ & Risk assessment & Slow risk identification \\
\hline & Control constraint & $\begin{array}{l}\text { Budget control constraint } \\
\text { Accounting systems control } \\
\text { constraint } \\
\text { Contract control constraint }\end{array}$ & Control activities & $\begin{array}{l}\text { Improper control of scientific } \\
\text { research expenditure process }\end{array}$ \\
\hline & $\begin{array}{l}\text { Psychological } \\
\text { constraint }\end{array}$ & $\begin{array}{l}\text { External psychological } \\
\text { constraint }\end{array}$ & $\begin{array}{l}\text { Information and } \\
\text { communication }\end{array}$ & $\begin{array}{l}\text { Poor information flow of the } \\
\text { scientific research management } \\
\text { department }\end{array}$ \\
\hline & $\begin{array}{l}\text { Regulatory } \\
\text { constraint }\end{array}$ & $\begin{array}{c}\text { Horizontal regulatory } \\
\text { constraint } \\
\text { Vertical regulatory constraint } \\
\text { internal and external regulatory } \\
\text { constraint }\end{array}$ & Internal supervision & Ineffective supervision \\
\hline
\end{tabular}

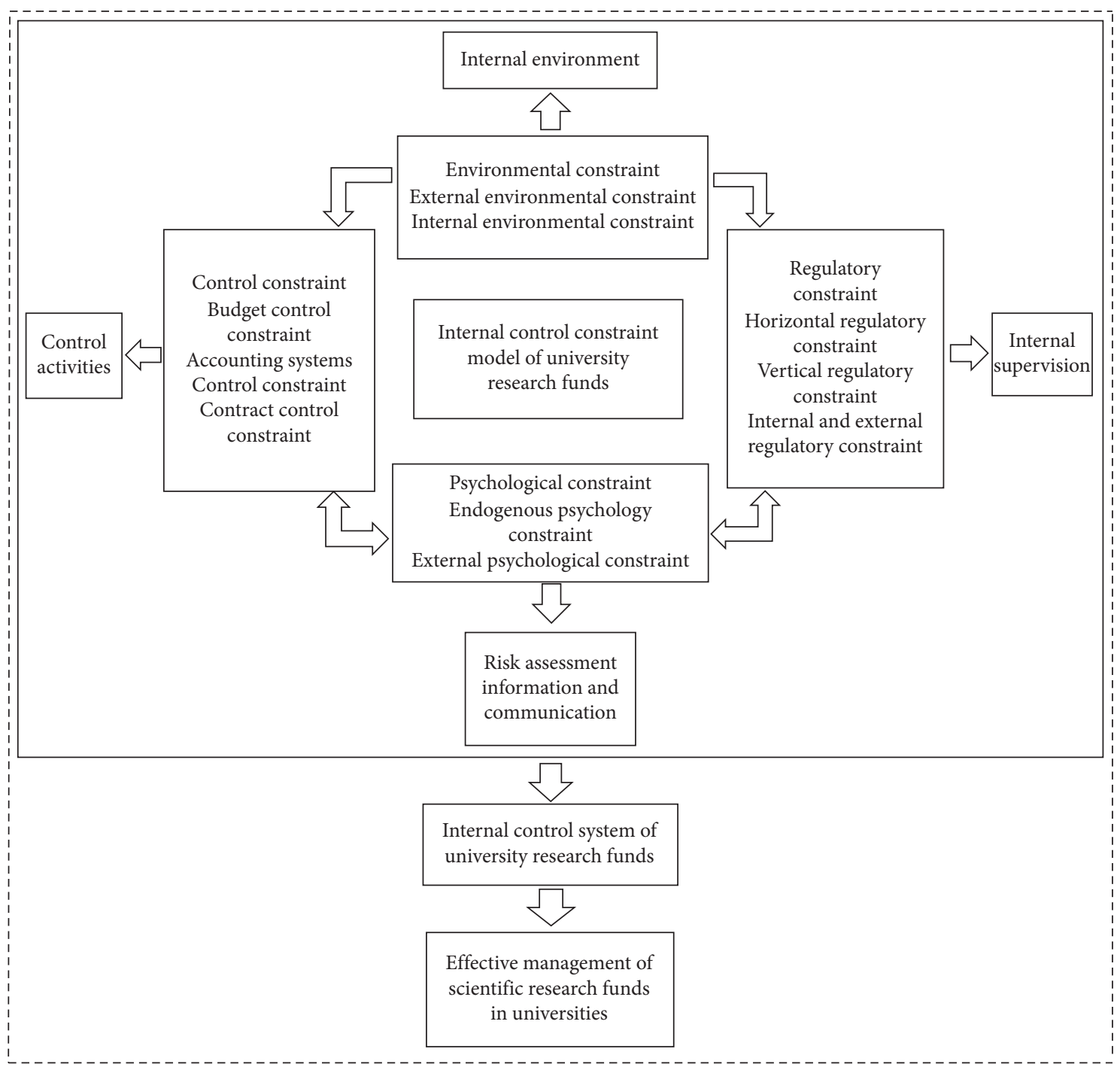

FIGURE 1: Internal control constraint model of research funds in universities (EPCR model). 
management authority and responsibility among the scientific research management departments, colleges, and other departments, so as to jointly supervise the scientific research activities. (2) Horizontal regulatory constraint mainly refers to the constraints on scientific research behaviours formed by mutual supervision among members of each research group. While improving the vertical supervision mechanism, universities should also take into account the horizontal supervision mechanism. They should take relevant measures to solve the problem of information asymmetry between the leaders of research groups and their members and strictly require the leaders of research groups to share information timely. Simultaneously, reasonable reporting channels are set up to ensure that violations of laws and regulations can be timely reflected and resolved. (3) Internal and external regulatory constraint mainly refers to the behaviour constraints formed by the joint supervision of the university and offcampus cooperative enterprises on the behaviours of the participants in the university's scientific research activities. The supervision of off-campus cooperative enterprises is mainly manifested in the supervision of contract signing and performance, but the off-campus cooperative enterprises lack the motivation of supervision. So, universities should cooperate with specific enterprises to jointly supervise scientific research behaviours or scientifically set corresponding reward methods, so as to improve the enthusiasm of supervision of off-campus cooperative enterprises.

\section{Conclusion}

In this paper, three cases of corruption of university research funds are studied by case study method. Based on the five elements of COSO internal control system, the EPCR model is constructed. Moreover, the model is explained in detail from four modules of environmental constraint, psychological constraint, control constraint, and regulatory constraint. It is hoped that the existing internal control system of universities is improved through the construction of the model.

From the perspective of theory, the current academic circles lack comprehensive and systematic research on the internal control of university research funds and fail to provide scientific model guidance. This study studies and constructs EPCR model from the perspective of corruption cases in university scientific researches. Therefore, this study enriches the research perspective of future related research and provides some theoretical guidance for the model.

From the perspective of practice, the EPCR model constructed in this paper provides relevant suggestions for the construction of the internal control system of scientific research funds in universities from the five elements of internal environment, risk assessment, control activities, information and communication, and internal environment. Moreover, the suggestion is based on the actual situation and a comprehensive study of many university research corruption cases, so it has a certain pertinence, comprehensiveness, and feasibility.
This paper studies only three typical cases of scientific research corruption in universities and cannot fully identify the deficiencies in the existing internal control system of scientific research funds in universities. The interaction between the elements of each module is not discussed in detail. In the future, more cases can be used to further explore the model according to its generation mode and characteristics in different ages.

\section{Data Availability}

The data used to support the findings of this study are available from the corresponding author upon request.

\section{Conflicts of Interest}

The authors declare that they have no conflicts of interest.

\section{Acknowledgments}

This work was supported by the National Philosophy and Social Science Foundation (18BGL079); Natural Science Foundation of Jiangxi Province (20192BAA208003); and Humanities and Social Sciences Foundation of Jiangxi Colleges and Universities (JJ20119).

\section{References}

[1] Z. Lin, “"Stakeholder” theory logic and mechanism reengineering of internal control," Friends of Accounting, vol. 17, pp. 8-19, 2020.

[2] X. Tian, "Summary and enlightenment of internal control theory in administrative institutions," Finance and Accounting, vol. 9, pp. 14-16, 2013.

[3] C. Li and L. Chang, "Research on the operation mechanism of first-rate discipline construction funds based on internal control and risk management," Journal of Dalian University of Technology (Social Science Edition), vol. 41, no. 0, pp. 17-24, 2020.

[4] Y. Li, "Research on internal control mechanism of colleges and universities from the perspective of integrity," Friends of Accounting, vol. 18, pp. 93-98, 2020.

[5] Y. Zou, "Research on the business process of internal control of university research funding under the background of "empowerment, regulation and service"--taking horizontal research funding as an example," Accountants, vol. 22, pp. 50-52, 2019.

[6] W. Yang and C. Xie, "Risk control of university research funds under government accounting system: from the perspective of internal control," Business Accounting, vol. 2, pp. 64-67, 2020.

[7] H. T. L. Nguyen and V. L. Meek, "Key problems in organizing and structuring university research in Vietnam: the lack of an effective research "behaviour formalization" system," Minerva, vol. 54, no. 1, pp. 45-73, 2016.

[8] O. Henk, "Internal control through the lens of institutional work: a systematic literature review," Journal of Management Control, vol. 31, no. 3, pp. 239-273, 2020.

[9] L. B. Leonce, N. L. Kenneth, and J. Z. Chad, "Sarbanes-Oxley and corporate risk-taking," Journal of Accounting and Economics, vol. 49, no. 1, pp. 34-52, 2010.

[10] H. Sun and Y. Zhu, "The theory and application of case study method," Scientific Management Research, vol. 1, pp. 116-120, 2004. 